\title{
HASIL KAJIAN SINTAKSIS NOVEL SELAMAT TINGGAL KARYA TERE LIYE SEBAGAI BAHAN AJAR MATA PELAJARAN BAHASA INDONESIA
}

\author{
Fathia Rosyida ${ }^{1}$, Sutrimah ${ }^{2}$, Garwati $^{3}$ \\ ${ }^{1}$ Fakultas Pendidikan Bahasa dan Seni, IKIP PGRI Bojonegoro \\ email: fathia.rosyida@ikippgribojonegoro.ac.id \\ ${ }^{2}$ Fakultas Pendidikan Bahasa dan Seni, IKIP PGRI Bojonegoro \\ email: sutrimahyusuf@yahoo.com \\ ${ }^{3}$ Fakultas Pendidikan Bahasa dan Seni, IKIP PGRI Bojonegoro \\ email: garwats123@gmail.com
}

\begin{abstract}
Novels can be interpreted as a form of literary work written by the author without releasing the intrinsic and extrinsic elements. For this reason, the purpose of this study is to find out 1) the form of phrases, clauses, and sentences in Tere Liye's novel entitled Selamat Tinggal 2) the results of the study of Tere Liye's novel entitled Selamat Tinggal can be used as teaching materials for Indonesian language subjects. This research is a qualitative research using listening, engaging, and proficient techniques starting from steps 1) preparation, 2) data collection, and 3) data analysis. The conclusions of this research are (1) Tere Liye's novel entitled Selamat Tinggal contains elements of phrases, clauses, and sentences. Phrases in Tere Liye's novel entitled Selamat Tinggal are verb phrases, noun phrases, adjective phrases, numeral phrases, endocentric phrases, and exocentric phrases. The clause in Tere Liye's novel entitled Selamat Tinggal is in the form of positive and negative clauses. Sentences in Tere Liye's novel entitled Selamat Tinggal are sentences based on 1) pronunciation, 2) grammatical structure or number of phrases, 3) function, 4) elements, 5) arrangement, 6) style or form of presentation, 7) subject. (2) The results of the study of Tere Liye's novel entitled Selamat Tinggal can be used as teaching materials for Indonesian language subjects from elementary to high school levels based on KI and KD at each level of education.
\end{abstract}

Keywords: Novel entitled Selamat Tinggal, Tere Liye, Syntax, teaching material, Indonesian language subject

\begin{abstract}
Abstrak: Novel dapat dimaknai sebagai bentuk karya sastra yang ditulis oleh pengarang dengan tidak melepaskan unsur intrinsik dan ekstrinsik. Untuk itu tujuan dari penelitian ini adalah ingin mengetahui 1) bentuk frasa, klausa, dan kalimat pada novel Selamat Tinggal karya Tere Liye, 2) hasil kajian novel Selamat Tinggal karya Tere Liye dapat dijadikan sebagai bahan ajar mata pelajaran bahasa Indonesia. Penelitian ini merupakan penelitian kualitatif dengan menggunakan teknik simak, libat, dan cakap dengan dimulai dari langkah 1) persiapan, 2) pengumpulan data, dan 3) analisis data. Simpulan penelitian ini adalah (1) Novel Selamat Tinggal karya Tere Liye mengandung Unsur frasa, klausa, dan kalimat. Frasa pada novel Selamat Tinggal karya Tere Liye berupa frasa verba, frasa nomina, frasa adjektiva, frasa numeralia, frasa endosentris, frasa eksosentris. Klausa pada novel Selamat Tinggal karya Tere Liye berupa klausa positif dan negatif. Kalimat pada novel Selamat Tinggal karya Tere Liye berupa kalimat yang didasarkan pada 1) pengucapan, 2) struktur gramatikal atau jumlah frasa, 3) fungsi, 4) unsur, 5) susunan, 6) gaya atau bentuk penyajian, 7) subjek. (2) Hasil kajian novel Selamat Tinggal karya Tere Liye dapat dijadikan sebagai bahan ajar mata pelajaran bahasa Indonesia mulai jenjang sekolah dasar hingga menengah atas berdasarkan KI dan KD pada setiap jenjang pendidikan tersebut.
\end{abstract}

Kata Kunci: Novel Selamat Tinggal, Tere Liye, sintaksis, bahan ajar, mata pelajaran bahasa Indonesia 


\section{PENDAHULUAN}

Novel merupakan suatu karya sastra yang mempunyai unsur intrinsik dan ekstrinsik yang yang berbentuk kata-kata atau tulisan (Oktarina, 2009). Novel merupakan jenis sastra yang dibangun melalui unsur intrinsik serta dunia imajinatif yang didealkan dari tampilan kehidupan dunia (Akbar, 2012). Novel merupakan salah satu pemanfaatan bahasa dan gaya bahasa yang ditulis oleh seorang novelis untuk menyampaikan sebuah ide (Ibrahim, 2011). Novel merupakan sebuah cerita yang didalamnya memiliki tujuan memberikan nilai estetis dan menghibur khalayak (Sari, 2017). Di dalam novel selalu ada peristiwa yang terjadi di masa lalu dan di dalam novel terdapat pengalaman dan pengetahuan untuk menyegarkan kembali sejarah serta agar pembaca mendapatkan pengetahuan tersebut (Silfia, 2015).

Salah satu novel yang pernah dibaca dan menjadi bahan dalam penelitian ini yaitu novel Selamat Tinggal, novel Selamat Tinggal adalah novel yang ditulis oleh seorang penulis ternama di Indonesi yaitu Tere Liye. Novel ini bergenre Romance

Novel tersebut terbilang baru sehingga kami melakukan penelitian ini menggunakan kajian sintaksis. Sintaksis merupakan suatu cabang ilmu linguistik yang membahas tentang susunan kata dalam kalimat (Arifin \& Junaiyah 2008). Sintaksis menurut Menurut Urdang dalam Nurhayati (2019) sintaksis ialah suatu ilmu yang mempelajari bahasa dalam sebuah kalimat atau frasa. Ilmu yang berkaitan dengan kajian kata, frasa, klausa dan kalimat disebut dengan sintaksis.

Setelah kami membaca beberapa referensi penelitian, kami memutuskan untuk meneliti novel Selamat Tinggal karya Tere Liye menggunakan kajian sintaksis yang belum pernah diteliti sebelumnya.

Di dalam sintaksis terdapat objek kajian yaitu Frasa, Klausa, dan kalimat. Berikut adalah pengertian dari frasa. Frasa merupakan pengisi fungsi sintaksis Istilah frasa Yang berbentuk dari dua kata atau lebih (Wahidah, 2019). Frasa ialah kata yang tidak melebihi batas suatu fungsi dimana kata tersebut digabung dengan kata yang lain (Darwin, 2017).

Berkaitan dengan penelitian kami tentang kajian sintkasis, terdapat tiga objek kajian yaitu Frasa, Klausa, dan Kalimat. Berkenaan dengan hal tersebut seorang peneliti bernama Rati melakukan penelitian tentang analisis Novel Supernova Akar Karya Dewi Lestari dengan membahas frasa endosentris dan eksosentris. Berhubungan dengan hal tersebut kami melakukan penelitian menggunakan objek kajian frasa pada novel Selamat Tinggal karya Tere Liye yang belum pernah diteliti oleh peneliti lain.

Selanjutnya yaitu definisi klausa. Chaer dalam Darwin (2017) mengatakan bahwa klausa masuk dalam satuan di atas frasa dan satuan di bawah kalimat, dan kata yang berkonstruksi predikat. Menurut Ramlan Klausa merupakan suatu gramatikal yang memiliki unsur SPOK atau SPO (Rinata, dkk., 2019).

Selain frasa juga terdapat klausa untuk diteliti. Maryam yang juga menganalisis klausa kompleks dalam novel No greater love karya Danielle Steel. Kami juga melakukan hal yang sama yaitu menganilisis klausa pada novel Selamat Tinggal karya Tere Liye.

Definisi dari Kalimat oleh beberapa ahli sebagai berikut. Siregar (2016) mengatakan bahwa kalimat ialah suatu pikiran yang membentuk satuan bahasa dan memiliki amanat. Menurut Purba (2016) suatu gabungan beberapa kata untuk mengungkapkan suatu tujuan. Selain itu Hariyadi (2016) mengatakan bahwa kalimat merupakan susunan konstituen dasar yang membentuk satuan sintaksis, yang berupa klausa, dengan konjungsi, serta intonasi final.

Dari beberapa objek kajian yang telah disebutkan Wardani (2018) meneliti kompleksitas dalam novel the secret of detya 2: back to the secret karya Kinta. Maka kami juga melakukan penelitian tentang analisis kalimat pada novel Selamat Tinggal karya Tere Liye.

Dengan demikian kami melakukan penelitian ini agar mampu memahami kajian sintaksis yang berupa Frasa, Klausa, 
dan kalimat pada novel Selamat tinggal Karya Tere Liye.

\section{METODE PENELITIAN}

Penelitian ini termasuk penelitian kualitatif dengan menggunakan metode deskriptif. Di mana penelitian ini mendeskripsikan untuk mengidentifikasi, menganalisis, dan mengklasifikasi data. Penelitian kualitatif merupakan metode yang menekankan pemahaman pada suatu masalah. Metode deskriptif ialah proses penelitian yang berupa penjelasan tertulis dan mendeskripsikan data.

Data pada penelitian ini berupa frasa, klausa, dan kalimat yang bersumber dari novel Selamat Tinggal karya Tere Liye dikumpulkan dengan menggunakan teknik simak, libat, dan cakap.

Secara garis besar, langkah penelitian ini sebagai berikut.

\section{Persiapan}

Tahap persiapan ini, peneliti membaca artikel yang berhubungan penelitian sintaksis. Tidak hanya itu, peneliti juga membaca penelitian orang lain tentang frasa, klausa, dan kalimat. Peneliti membaca beberapa referensi dari internet untuk memperluas wawasan mengenai penelitian kami. Untuk referensi lain peneliti juga membaca skripsi dari repository beberapa universitas. Kemudian, peneliti membaca novel Selamat Tinggal karya Tere Liye (2020) yang termasuk novel yang akan kami teliti.

\section{Pengumpulan data}

Pada tahap pengumpulan data ini, peneliti mengumpulkan data dengan memberi garis bawah atau dengan memberi tanda titik pada bacaan yang mengandung frasa, klausa, dan kalimat. Setelah itu, kami mengumpulkan data dengan menulis atau mengetik bacaan yang mengandung frasa, klausa, dan kalimat pada kertas dan halaman yang kosong. Selanjutnya kami juga melihat kembali contoh yang benar dan melihat ulang bacaan yang telah kita ambil, apakah data tersebut sudah benar atau belum. Jika semua sudah baru kita masukkan dalam pengumpulan data.
Analisis data

Setelah kami melalui proses pesiapan, dan pengumpulan data maka sekarang waktunya kita untuk mengambil beberapa contoh dari bacaan novel yang telah kita baca untuk memenuhi kajian sintaksis yang berupa frasa, klausa, dan kalimat. Dengan beberapa contoh yang kami ambil, kami akan menganalisis data tersebut menggunakan diagram pohon agar kami mengetahui fungsi dan kategorinya. Pada tahap analisis data ini peneliti analisis frasa, klausa, dan kalimat dalam bacaan sehingga kami fokus dalam tiga objek kajian dari sintaksis tersebut karena peneliti ingin melihat detai dari analisis kami tentang frasa, klausa, dan kalimat yanga dalam bacaan novel Selamat Tinggal karya Tere Liye.

\section{HASIL DAN PEMBAHASAN}

Setelah melihat metode dari penelitian ini, peneliti menentukan hasil penelitian pada novel Selamat Tinggal karya Tere Liye sebagai berikut

\section{Hasil Kajian Sintaksis Novel Selamat Tinggal Karya Tere Liye}

Hasil kajian sintaksis pada novel Selamat Tinggal karya Tere Liye dapat dijelaskan dari unsur frasa, klausa, dan kalimat.

Frasa pada novel Selamat Tinggal Karya Tere Liye

Berdasar dari hal tersebut frasa yang berdasarkan pada unsur inti dapat dibedakan, 1) Frasa Verba. Frasa verba merupakan sebuah frasa yang berisi predikat dari kalimat atau klausa (Hasanudin, 2018). Contoh predikat dapat dilihat pada kata pelaksanan dan implementasi (Daimuntaha, Darmuki, Hasanudin, 2019). Kata ini dapat berubah fungsi menjadi frasa saat mendapat imbuhan kata lain, misalnya ada pelaksanaan atau masih diimpementasi.

Setelah menganalisis novel Selamat Tinggal karya Tere Liye terdapat frasa "masih menyimpan" (Liye, 2020). Frasa tersebut dapat digolongkan ke dalam frasa verba. 2) Frasa nomina. frasa nomina ialah suatu bentuk nomina dalam frasa induk 
(inti). Contoh frasa nomina setelah kami menganalisis novel Selamat Tinggal karya Tere Liye, yaitu sebagai berikut: "toko buku bajakan" (Liye, 2020). Dari contoh tersebut frasa yang bercetak miring yaitu buku bajakan, merupakan golongan frasa benda (nomina). 3) frasa adjektiva adalah kelompok dari beberapa kata yang berfungsi untuk menjelaskan yaitu sangat, paling, lebih, kurang, harus, dapat, dan agak dibentuk dari kata sifat (kata yang diterangkan). Berdasar pada analisis peneliti pada novel Selamat Tinggal karya Tere Liye terdapat frasa "wah, sangat mahal, bang" (liye, 2020) frasa yang bercetak miring tersebut termasuk ke dalam frasa adjektiva. 4) frasa numeralia merupakan frasa yang memiliki peran sama dengan kata nomor atau bilangan atau numeralia. Berdasar pada analisis novel Selamat Tinggal karya Tere Liye peneliti menemukaan contoh dari frsa numeralia, yaitu: "enam tahun kamu kuliah" (Liye, 2020), frasa yang bercetak miring yaitu enam tahun termasuk dalam kelompok frasa numeralia.

Menurut hubungannya antara unsurunsur frasa dapat dibedakan menjadi berikut: pertama, frasa Endosentris. Frasa endosentris menurut Ramlan dalam Hasanudin (2018) merupakan frasa yang peranan atau distribusinya sama dengan satu unsur dengan semua unsurnya. Mengandung arti bahwa satu unsur yang terdapat di dalamnya sudah mewakili dari seluruh unsur yang ada. Pada frasa endosentris juga memiliki tiga jenis, yaitu frasa atributif, koordinatif, dan apositif.

Frasa atributif ialah frasa yang hanya mengandung satu inti suatu unsur saja. Berdasarkan pada analisis peneliti novel Selamat Tinggal karya Tere Liye kami mnemukan contoh frasa atributif, yaitu "rambut berubannya" (liye, 2020). Contoh rambut berubannya termasuk dalam frasa atributif karena pola kalimat tersebut sudah tidak bisa diberi kata penghubung di dalamnya.

Frasa koordinatif merupakan frasa yang terbentuk dari unsur yang mempunyai kedudukan sama. Kesetaraannya dibuktikan oleh kata penghubung dan atau atau yang menghubungkan unsur tersebut.
Berdasarkan penelitian kami pada novel Selamat Tinggal karya Tere Liye frasa koordinatif seperti berikut "di dunia bajakan, harga buku hanya dilihat dari tebal atau tipisnya saja" (Liye, 2020). Frasa tebal atau tipis merupakan bentuk dari frasa koordinatif.

Frasa apositif adalah jenis frasa endosentris yang komponen luar bahasanya menunjukkan wujud sama. Pada analisis novel Selamat Tinggal karya Tere Liye, yaitu "sintong! Lama tidak melihat wajah jelekmu, boss" (Liye, 2020) pada contoh kalimat tersebut unsur pusatnya terletak pada Sintong serta boss pada kalimat tersebut boss termasusk kata unsur aposisi atau apositif. Sebab kata Sintong sudah bisa menjadi pengganti boss.

Kedua, frasa eksosentris merupakan frasa yang tidak dapat menggantikan posisinya dalam suatu kalimat sebab tidak memiliki unsur langsung di dalamnya. Berdasarkan analisis kami dalam novel Selamat Tinggal karya Tere Liye memiliki contoh yaitu "harta karun" (Liye, 2020). Pada contoh harta karun, memiliki satu unsur karena peranannya sama.

\section{Klausa pada novel Selamat Tinggal Karya Tere Liye}

Unsur yang selanjutnya yaitu klausa. Klausa yang terdapat pada novel Selamat Tinggal karya Tere Liye ada dua macam yaitu berupa klausa negatif dan positif. Klausa negatif merupakan klausa yang kehadirannya ditandai oleh unsur negasi pada $\mathrm{P}$ dinegatifkan. Pada analisis novel Selamat Tinggal karya Tere Liye terdapat contoh dari klausa negatif yaitu "kami tidak punya uang' (Liye, 2020:159). Contoh dari klausa negatif tersebut mengandung negasi pada $\mathrm{P}$, sehingga klausa tersebut termasuk ke dalam klausa negatif.

Klausa positif ialah klausa yang tidak menegatifkan $\mathrm{P}$ atau tidak memiliki unsur negasi dalam kalimatnya. Contoh dari klausa positif pada novel Selamat Tinggal karya Tere Liye yaitu "Sintong menatap sekitar" (Liye, 2020). Klausa tersebut memiliki unsur Sintong menempati fungsi $\mathrm{S}$, kata menatap menempati fungsi $\mathrm{P}$, dan kata sekitar menempati fungsi K. Klausa tersebut termasuk ke dalam klausa positif 
karena klausa tersebut tidak memiliki fungsi negasi atau Predikatnya tidak dinegatifkan.

\section{Kalimat pada novel Selamat Tinggal Karya Tere Liye}

Pada novel Selamat Tinggal karya Tere Liye terdapat bentuk kalimat yang berdasarkan pada 1) pengucapan, 2) struktur gramatikal atau jumlah frasa, 3) fungsi, 4) unsur, 5) susunan, 6) gaya atau bentuk penyajian, 7) subjek. Hal ini dapat dijelaskan sebagai berikut.

Pertama, Kalimat yang berdasar pada pengucapan terdiri atas dua, yaitu kalimat tidak langsung dan kalimat langsung. Kalimat tidak langsung memiliki definisi sebagai kalimat yang diinformasikan oleh pihak kedua dari pihak pertama dan disalurkan ke pihak ketiga. Kalimat tidak langsung memiliki ciri-ciri dengan menggunakan kata "bahwa". Setelah menganalisis novel Selamat Tinggal karya Tere Liye peneliti dapat menemukan kalimat tidak langsung. Sintong menyeringai, meletakkan ransel kumal (Liye, 2020). Pada kalimat tersebut tokoh Sintong sedang bercakap dengan sesorang yang telah diceritakan oleh pengarang. Dimana pengarang menceritakan kegiatan dan percakapan sintong dengan temannya, apa yang telah diucapkan oleh orang pertama akan disalin oleh orang kedua kemudian diinformasikan kepada orang ketiga. Pada kalimat inilah novel Selamat Tinggal karya Tere Liye telah terbukti bahwa mengandung suatu kalimat yang tidak langsung.

Kalimat langsung memiliki arti sebagai kalimat yang langsung diucapkan oleh pihak pertama kepada pendengar. Dari analisis novel Selamat Tinggal karya Tere Liye memiliki contoh sebagai berikut: "Bagaimana tadi? Lancar ketemu dekannya?" (Liye, 2020). Pada kalimat tersebut terbukti bahwa pihak pertama bertanya langsung dengan pihak yang ditanya. Sehingga kalimat tersebut dikatakan sebagai kalimat langsung.

Kedua, Kalimat berdasarkan pada struktur gramatikal atau jumlah frasa ada dua jenis, yaitu kalimat majemuk dan kalimat tunggal. 1) kalimat majemuk merupakan kalimat yang terdiri dari beberapa klausa. Berdasar pada sifatnya, kalimat majemuk terbagi menjadi tiga, yaitu kalimat majemuk yang setara, kalimat majemuk bertingkat, dan kalimat majemuk campuran.

Kalimat majemuk dikatakan setara apabila kalimat tersebut ditandai konjungsi dan, atau, tetapi serta terdiri atas dua klausa seimbang. Berdasar pada analisis novel Selamat Tinggal karya Tere Liye ditemukan contoh dari kalimat majemuk setara yaitu sebagai berikut: "tidak hanya pengunjung di pasar Senen, atau mahasiswa yang lewat di gang kecil" (Liye, 2020), kalimat tersebut memiliki konjungsi atau. Kalimat tersebut memiliki pola tidak hanya pengunjung sebagai S, di pasar Senen sebagai K, atau sebagai konjungsi, mahasiswa yang lewat sebagai $\mathrm{S}$, dan di gang kecil sebagai $\mathrm{K}$. Sehingga terbukti bahwa pada novel Selamat Tinggal karya Tere Liye terdapat kalimat majemuk setara.

Kalimat majemuk bertingkat ialah kalimat yang polanya berhubungan tidak sederajat, induk kalimat untuk bagian yang lebih tinggi sedangkan anak kalimat untuk bagian yang lebih rendah. Pada analisis novel Selamat Tinggal karya Tere Liye terdapat contoh kalimat majemuk bertingkat, yaitu "Dibandingkan hujan, ketika tempias air menyeberang" (Liye, 2020), kalimat tersebut memiliki konjungsi ketika yag merupakn ciri-ciri dari kalimat majemuk bertingkat. Kalimat tersebut dibangun dua klausa yaitu dibandingkan hujan sebagai induk kalimat, dan ketika tempias menyeberang termauk anak kalimat.

Kalimat majemuk campuran adalah bentuk kalimat yang berasal dari gabungan kalimat majemuk bertingkat dan setara. Berdasarkan hasil analisis pada novel Selamat Tinggal karya Tere Liye. Peneliti tidak menemukan bentuk kalimat majemuk campuran.

Kalimat tunggal ialah kalimat yang terdapat satu klausa atau konstituen dari subjek dan kalimat. Pada Novel Selamat Tinggal karya Tere Liye ada contoh dari kalimat tunggal yaitu "Dua pembeli itu mengangguk" (Liye, 2020). Pada kalimat tesebut memiliki konstituensi $\mathrm{S}$ dan $\mathrm{P}$ yaitu 
dua pembeli sebagai $\mathrm{S}$ dan mengangguk sebagai $\mathrm{P}$ sehingga dapat dikatakan kalimat tunggal.

Ketiga, Kalimat yang berdasarkan pada fungsinya dibedakan menjadi dua yaitu, kalimat seruan, tanya, berita, dan kalimat perintah.

Kalimat perintah dijelaskan oleh penutur sebagai perintah untuk mitra tutur. Kalimat perintah merupakan kalimat yang kita sampaikan kepada seseorang untuk menghendaki yang kita inginkan. Analisis novel Selamat Tinggal karya Tere Liye dapat ditemukan contoh kalimat perintah yaitu: "Ayo ambil yang banyak nasinya, Nak Sintong" (Liye, 2020). Kalimat tersebut termasuk dalam kalimat perintah, yaitu menggunakan kalimat ayo ambil.

Kalimat berita juga dapat disebut kalimat pemberi informasi untuk orang atau kalimat yang bisa dijawab dari pertanyaan "Askamediga" juga terdapat tanda titik di belakang kalimat. Berikut adalah contoh dari kalimat berita yang terdapat pada novel Selamat Tinggal karya Tere Liye: "Gadis berambut panjang" (Liye, 2020). Kalimat tersebut adalah jawaban atas pertanyaan "Siapakah Jess itu?" Jawaban tersebut terdapat tanda titik pada akhir kalimat yang termasuk kalimat berita.

Kalimat tanya ialah kalimat yang berisi tentang pertanyaan seseorang dan ditandai adanya tanda tanya "?" di belakang kalimat. Kalimat tanya menurut Hasanudin dan Widyaningrum (2020) adalah kalimat pertanyaan untuk orang lain agar mendapat respons. Berikut ni contoh dari kalimat tanya yang ada pada novel Selamat Tinggal karya Tere Liye : "Memangnya kamu tau dunia selebgram?" (Liye, 2020). Kalimat tanya tersebut berguna untuk memastikan bahwa seseorang itu mengetahui suatu hal atau tidak.

Kalimat seruan ialah suatu tanda kekaguman perasaan seseorang pada suatu hal dan biasanya terdapat tanda (!) pada akhir kalimat. Berikut contoh dari kalimat seruan yang terdapat pada Novel Selamat Tinggal karya Tere Liye: "Terima kasi, pak!” (Liye, 2020). Kalimat yang tertera menunjukkan bahwa seseorang itu kagum dengan salah satu tokoh.

Keempat, terdapat dua jenis kalimat yang berdasakan unsurnya, yaitu kalimat tidak lengkap dan kalimat lengkap.

Kalimat lengkap yaitu termasuk kalimat yang susunanya lengkap, paling tidak memiliki S dan P. Berikut ini contoh dari kalimat lengkap yang terdapat pada novel Selamat Tinggal karya Tere Liye: "Sintong meraih bolpoin dari dalam ransel" (Liye, 2020). Kalimat tersebut memiliki pola S P O K, yaitu Sintong sebagai S, meraih sebagai $\mathrm{P}$, bolpoin sebagai $\mathrm{O}$, dalam ransel sebagai K. Sehingga terbukti bahwa kalimat tersebut merupakan kalimat lengkap.

Kalimat tidak lengkap merupakan kalimat yang tidak terdapat klausa di dalamnya. Setelah menganalisis, berikut ini contoh dari kalimat tidak lengkap pada novel Selamat Tinggal karya Tere Liye: "Begitulah mama" (Liye, 2020). Kalimat ini merupakan kalimat tidak lengkap karena tidak memiliki struktur klausa yang membangunnya.

Kelima, terdapat dua jenis kalimat berdasarkan susunannya, yaitu versi (kalimat yang susunan unsur/pola tidak terbalik) dan inversi (kalimat yang susunan unsur/pola terbalik). Kalimat versi merupakan kalimat yang memiliki pola kalimat beraturan. Berdasarkan analisis berikut adalah contoh dari kalmat versi: "Sintong menelan ludah" (Liye, 2020). Kalimat tersebut memiliki kaidah kebahasaan yaitu S P O, Sintong sebagai S, menelan sebagai $\mathrm{P}$, dan ludah Sebagai $\mathrm{O}$. Berdasarkan urain tersebut terbukti bahwa kalimat tersebut termasuk kalimat yang beraturan atau kalimat versi.

Kalimat inversi ialah kalimat yang berpola tidak beraturan. Berdasarkan hasil analisis. Berikut contoh kalimat inversi pada novel Selamat Tinggal karya Tere Liye: "bareng bunga" (Liye, 2020:71). Kalimat tersebut terdapat kalimat yang polanya mendahului pola lain, yaitu dengan pola P S, Bareng sebagai P dan Bunga sebagai S. Sehingga kalimat tersebut dikatakan atau tergolong dalam kalimat inversi karena pada pola P S Predikat mendahului subjek yang ada. 
Keenam, terdapat tiga jenis kalimat berdasarkan gaya atau bentuk penyajiannya, yaitu kalimat melepas, klimaks, dan berimbang.

Kalimat melepas merupakan kalimat yang terdiri atas induk kalimat yang berada di depan dan anak kalimat mengikuti induk kalimat yang termasuk dalam kalimat majemuk.

Kalimat klimaks adalah kalimat yang berawal dari rincian dan diikuti inti penting informasi. Berdasarkan analisis berikut contoh dari kalimat klimaks novel Selamat Tinggal karya Tere Liye: "Lantas di usia dua belas tahun itu pula, Sutan Pane dan adiknya merantau ke Jakarta" (Liye, 2020). Pada kalimat tersebut terlihat jelas bahwa itu adalah contoh kalimat klimaks karena pembaca tidak akan paham dengan kalimat lantas di usia dua belas tahun secara keseluruhan, jika dengan menggunakan induk kalimatnya pembaca akan memahami maksud anak kalimat. Hal tersebutlah yang termasuk dalam ciri-ciri sebuah kalimat klimaks.

Kalimat berimbang adalah kalimat yang disusun dalam kalimat majemuk campuran dan kalimat majemuk setara. Penyajian inilah yang memperlihatkan kesajajaran informasi dan bentuknya. Berdasarkan analisis. Berikut contoh kalimat berimbang pada novel Selamat Tinggal karya Tere Liye: "Gadis secantik dan sepintar ini" Pada kalimat tersebut menunjukkan adanya konjungsi dan, konjungsi tersebut termasuk ciri dalam kalimat majemuk setara yang memperlihatkan bahwa kalimat tersebut sejajar atau berimbang. Sehingga kalimat tersebut termasuk dalam kalimat seimbang dengan pola kalimat majemuk setara.

Ketujuh, kalimat juga terbagi menjadi dua bagian berdasarkan subjeknya, yaitu kalimat aktif dan pasif.

Kalimat aktif merupakan kalimat yang memiliki ciri menggunakan fungsi $\mathrm{P}$, yang ditandai imbuhan ber atau me pada $P$. Melihat dari fungsi predikatnya kalimat aktif juga dibagi menjadi tiga golongan:

Petama, kalimat aktif transitif. Kalimat aktif transitif ialah kalimat yang mementingkan adanya $\mathrm{O}$ dan biasanya pada $\mathrm{P}$ berimbuhan me. Berdasarkan analisis.
Berikut contoh kalimat aktif transitif pada novel Selamat Tinggal karya Tere Liye: "Bu Hardja menarik napas panjang" (Liye, 2020). Pada kalimat tersebut terdapat $\mathrm{Bu}$ Hardja sebagai S, Menarik sebagai $P$ yang termasuk dalam kalimat aktif transitif ditandai adanya me + tarik $=$ menarik dengan imbuhan me, dan napas panjang sebagai fungsi $O$. Dengan tidak adanya napas panjang maka kalimat $\mathrm{Bu}$ Hardja menarik menimbulkan pertanyaan, apa yang ditarik Bu Hardja?, maka jawabannya harus lengkap, jika kalimat tersebut ialah kalimat aktif transitif.

Kedua, kalimat aktif intransitif. Kalimat aktif intransitif merupakan kalimat yang tidak mementingkan fungsi dari $\mathrm{O}$ sehingga ada atau tidaknya $\mathrm{O}$ pada kalimat tersebut, kalimatnya akan tetap hidup atau berdiri sendiri. In pada intransitif merupakan serapan yang artinya tidak. Berdasarkan analisis. Berikut contoh kalimat aktif intransitif yaitu : "Petugas berseragam tadi malam bertugas ke sini" (Liye, 2020) kalimat tersebut hanya memiliki fungsi $\mathrm{S}$, $\mathrm{P}$, dan $\mathrm{K}$ sehingga tidak adanya fungsi $\mathrm{O}$ tetapi kalimat tersebut sudah bisa dipahami oleh pembaca.

Ketiga, kalimat aktif semitransitif. Kalimat aktif semitransitif memiliki arti sebagai kalimat yang setelah fungsi $\mathrm{P}$ terdapat pelengkap. Kalimat aktif semitransitif diwajibkan mengadakan pelengkap setelah predikat yang tertanda pada imbuhan ber yang ada pada fungsi $P$. Sebenarnya kalimat ini sama dengan kalimat aktif transitif hanya saja kalimat aktif transitif mewajibkan adanya $\mathrm{O}$ dan kata benda. Berdasarkan hasil analisis. Berikut ini adalah kalimat aktif semitransitif pada novel Selamat Tinggal karya Tere Liye: "Sintong bertemu Jess" (Liye, 2020:52) pada kalimat tersebut terdapat Sintong sebagai fungsi S, bertemu sebagai fungsi P dan Jess sebagai Pel. Pola kalimat di atas adalah SPPel. kehadiran pelengkap inilah yang menyebabkan bahwa kalimat di atas termasuk ke dalam kalimat aktif semitransitif.

Kalimat pasif ialah kalimat yang dengan adanya fungsi $\mathrm{P}$ fungsi $\mathrm{O}$ dapat sebagai pelaku dalam kalimat tersebut. kalimat ini juga memiliki fungsi $P$ yang 
berimbuhan di- dan ter-. Secara umum kalimat pasif ini dapat diubah dalam bentuk kalimat aktif dengan mengubah imbuhan $d i$ - menjadi me- pada P. Berdasarkan analisis. Berikut ini kalimat pasif pada novel Selamat Tinggal karya Tere Liye: "Lembaran kertas dengan judul tersebut tengah dibaca oleh pak Dekan" (Liye, 2020). Lembaran kertas dengan judul tersebut memiliki fungsi $\mathrm{S}$, tengah dibaca memiliki fungsi $\mathrm{P}$ dan oleh Pak Dekan memiliki fungsi $\mathrm{O}$. Kalimat tersebut termasuk kalimat pasif karena pada fungsi $\mathrm{S}$ ditukar dengan $\mathrm{O}$ serta dengan fungsi $\mathrm{P}$ pada kalimat tersebut berimbuhan $d i-$. Berikut penjelasannya

lembaran kertas dengan judul tersebut tengah dibaca oleh pak Dekan (SPO) bentuk kalimat pasif

Pak Dekan tengah membaca lembaran kertas dengan judul tersebut (SPO) bentuk kalimat aktif

Hasil penelitian di atas sejalan dengan hasil analisis Fitriana (2013) bahwa pada novel Perahu Kertas karya Dewi Lestari menggunakan pola kalimat yang sama dengan penelitian di atas. Hasil penelitian Wahyuni, Darmuki, \& Hasanudin (2019) menjelaskan bahwa pada Rubrik Opini Surat Kabar Harian Kompas terdapat bentuk kalimat tunggal dengan pola SPO, SPK, dan SPOPelK. Hasil penelitian Tasmin (2020) tentang adanya frasa pada sebuah cerita pendek karya siswa. Penelitian Budiman (2019) menjelaskan klausa pada sebuah novel karangan Ransom Riggs. Bahruddin (2018) juga pernah meneliti secara umum tentang sintaksis.

\section{Hasil Kajian Novel Selamat Tinggal Karya Tere Liye sebagai Bahan Ajar Mata Pelajaran Bahasa Indonesia}

Setelah melihat hasil kajian pada penelitian tersebut. Penelitian ini dapat dijadikan sebagai bahan ajar mata pelajaran bahasa Indonesia. Hal ini dapat dilihat pada uraian berikut.
Terlihat pada kelas 2 SD mata pelajaran Bahasa Indonesia. Pada KI 3. (Memahami pengetahuan faktual dengan cara mengamati (mendengar, melihat, membaca) dan menanya menurut rasa ingin tahu wacana dirinya, makhluk ciptaan Tuhan dan kegiatannya, dan benda-benda yang dijumpainya di rumah dan di sekolah) dan pada KD 3.2 (Menguraikan kosakata dan konsep wacana keragaman benda menurut bentuk dan wujudnya dalam bahasa Indonesia atau bahasa tempat melalui teks tulis, lisan, visual, dan/atau eksplorasi lingkungan. Dengan demikian peneliti yakin bahwa penilitian ini akan membantu siswa belajar dan mempelajari susunan Kalimat dengan tepat.

Lain hal dengan Sekolah Dasar, Sekolah Menengah Atas khususnya pada kelas 12 juga memiliki mata pelajaran bahasa Indonesia yang juga bisa menggunakan bahan ajar penelitin ini. Yaitu tertera pada KI 4 (Mencoba, mengolah, dan menyaji dalam ranah konkret (menggunakan, mengurai, merangkai, memodifikasi, dan membuat) dan ranah abstrak (menulis, membaca, menghitung, menggambar, dan mengarang) sesuai dengan yang dipelajari di sekolah dan sumber lain yang sama dalam sudut pandang/teori) KD 4.14 ( Menelaah struktur dan kebahasaan puisi rakyat (pantun, syair, dan bentuk puisi rakyat setempat) yang dibaca dan didengar). Dengan adanya penelitian ini bisa membantu memudahkan pembelajaran bahasa Indonesia SMP kelas 7 khususnya pada merangkai kata menjadi kalimat.

Pada SMA atau SLTA sederajat terdapat mata pelajaran yang membutuhkan bahan ajar yang cukup banyak karena pada jenjang ini keberanian siswa dalam membuat kalimat. Yaitu pada KD 4 ( (Mengolah, menalar, menyaji, dan mencipta dalam ranah konkret dan ranah abstrak terkait dengan pengembangan dari yang dipelajarinya di sekolah secara mandiri serta bertindak secara efektif dan kreatif, dan mampu menggunakan metode sesuai kaidah). Pada KD 4.8 (Menulis laporan tentang isi dan unsur sebuah buku nonfiksi). 
Selain itu ada beberapa peneliti menggunakan kajian sintaksis sebagai bahan ajarnya yaitu, pada penelitian Kiswadi (2016) menggunakan bahan ajar kajian sintaksis di SMPN 2 Kartasura. Pada penelitian ini, kajian sintaksis berperan penting di dalamnya karena pada kalimat lisan yang dituturkan mengandung kajian sintaksis.

Penelitian selanjutnya yaitu oleh Sastromiharjo (2020) Penelitian ini menggunakan kalimat sebagai bahan ajar untuk BIPA Thailand, berarti selain digunakan dalam bahasa Indonesia kalimat tunggal juga bisa digunakan untuk mancanegara. Penelitian Syarifah (2017) membahas tentang keterangan tempat pada kalimat bisa digunakan sebagai bahan ajar Siswa kelas VII. Pada penelitian Qudhori (2017) juga menunjukkan bahwa kajian digunakan sebagai inovasi bahan ajar siswa SMP Kelas VII agar siswa dapat belajar dengan bahan ajar yang bervariasi sehingga mereka tidak bosan..

\section{SIMPULAN}

Simpulan penelitian ini adalah (1) Novel Selamat Tinggal karya Tere Liye mengandung Unsur frasa, klausa, dan kalimat. Frasa pada novel Selamat Tinggal karya Tere Liye berupa frasa verba, frasa nomina, frasa adjektiva, frasa numeralia, frasa endosentris, frasa eksosentris. klausa pada novel Selamat Tinggal karya Tere Liye berupa klausa positif dan negatif. Kalimat pada novel Selamat Tinggal karya Tere Liye didasarkan pada 1) pengucapan, 2) struktur gramatikal atau jumlah frasa, 3) fungsi, 4) unsur, 5) susunan, 6) gaya atau bentuk penyajian, 7) subjek. (2) Hasil kajian novel Selamat Tinggal karya Tere Liye dapat dijadikan sebagai bahan ajar mata pelajaran bahasa Indonesia mulai jenjang sekolah dasar hingga menengah atas berdasarkan KI dan KD pada setiap jenjang pendidikan tersebut.

\section{DAFTAR RUJUKAN}

Akbar, S. (2012). Kajian sosiologi sastra dan nilai pendidikan dalam novel tuan guru karya Salman paris. Digital library. Retrieved from https://digilib.uns.ac.id/dokumen/det ail/29547/Kajian-Sosiologi-SastraDan-Nilai-Pendidikan-Dalam-NovelTuan-Guru-Karya-Salman-Faris

Arifatun, N. 2013. kesalahan penerjemahan teks bahasa indonesia ke dalam bahasa arab melalui gooogle translate (studi analisis sintaksis). journal of arabic language and arabic learning. 1(1). Retrieved from https://journal.unnes.ac.id/sju/index.p hp/laa/article/view/1506

Arifin, Z. \& Junaiyah. (2008). Sintaksis: untuk Mahasiswa Strata Satu Jurusan Bahasa atau Lingustik dan Guru Bahasa Indonesia SMA/SMK. Jakarta, Indonesia: Grasindo

Bahruddin, N. (2018). Konstruksi sintaksis pada novel sang pemimpi karya Andre Hirata. Skripsi. Fakultas keguruan dan ilmu keguruan Universitas Muhammadiyah Makassar. https://digilibadmin.unismuh.ac.id/up load/4537-Full_Text.pdf

Budiman, R, A. (2019). Analisis terjemahan klausa yang mengakomodasi respon terhadap tindak tutur ekspresif pada novel Miss peregrine's home for peculiar children Karya Ransom Riggs. Tesis. Program magister linguistik minat utama linguistik penerjemahan Pascasarjana universitas sebelas Maret, Surakarta. https://digilib.uns.ac.id/dokumen/do wnload/41451/MTM3NTAz/Analisis -Teknik-Penerjeman-Klausa-Relatifpada-Novel-The-Kite-Runner-SertaDampaknya-Terhadap-KualitasHasil-Terjemahannya-ahmad-YusufFirdaus.pdf 
Daimuntaha, D., Darmuki, A., \& Hasanudin, C. (2019). The Analysis Of Language Use Errors On Official Letters. Jurnal Kata: Penelitian tentang Ilmu Bahasa dan Sastra, 3(2), 170-177. Retrieved from

http://ejournal.1ldikti10.id/index.php/ kata/article/view/4305.

Darwin. (2017). Struktur klausa independen bahasa Indonesia. Jurnal bahasa dan sastra. 2(2). 25-38. Retrieved from https://core.ac.uk/download/pdf/2897 13941.pdf

Gani. (1986). Morfologi dan sintaksis kayu agung. Jepang. pusat pembinaan dan pengembangan bahasa.

Hariyadi, S. (2016). Unsur Kalimat pada Karangan Deskripsi Siswa Kelas VII D SMP Negeri 1 Arjasatahun Pelajaran 2015/2016. (Skripsi, Universitas Muhammadiyah Jember, Jember, Indonesia). Retrieved from http://repository.unmuhjember.ac.id/ 1467/8/Bab-I....pdf.

Hasanudin, C. (2018). Kajian sintaksis pada novel sang pencuri warna karya yersita. Jurnal Pendidikan Edutama, 5(2), 19-30. Doi http://dx.doi.org/10.30734/jpe.v5i2.1 91.

Hasanudin, C., \& Widyaningrum, H. K. (2020). Type of sentences on novel Dilan by Pidi Baiq. Jurnal Kata: Penelitian tentang Ilmu Bahasa dan Sastra, 4(2), 190-201. Retrieved from

http://ejournal.lldikti10.id/index.php/ kata/article/view/5180.

Ibrahim, S. (2011). Analisis gaya bahasa dalam novel mimpi bayang jingga karya Sanie B. Kuncoro. Surakarta. Rerieved from http://eprints.ums.ac.id/11547/1/HAL AMAN_DEPAN.pdf

Kiswadi. (2016). Kode, bahasa, dan jenis kalimat bahasa lisan Dosen pada situasi resmi: sebuah kajian sintaksis serta implementasi sebagai bahan ajar di SMPN 2 Kartasura. Skripsi. Fakultas keguruan dan ilmu pendidikan Universitas Muhammadiyah, Surakarta. http://eprints.ums.ac.id/44859/1/HAL AMAN\%20DEPAN.pdf

Nurhayati, D. (2019). Struktur klausa bahasa jawa di desa tolisu kecamatan toili Kabupaten Banggai. Jurnal bahasa dan sastra, 4(3). 70-78. Retrieved from https://core.ac.uk/download/pdf/2897 14032.pdf

Oktarina, Y. (2009). Nilai-nilai pendidikan islam dalam novel "laskar pelangi" karya Andrea Hirata. Surakarta. Retrieved from http://eprints.ums.ac.id/3546/1/G000 050110.pdf

Purba, S. D. K. (2016). Hubungan penguasaan kalimat efektif terhadap kemampuan mengubah kalimat ambigu menjadi kalimat efektif oleh siswa kelas VIII SMPTP. Mardi lestari medan tahun pelajaran 2015/2016. Repository Universitas HKBP Nommensen/ Retrieved from http://repository.uhn.ac.id/bitstream/ handle/123456789/643/Sry\%20Devi \%20Kristina\%20Purba.pdf?sequence $=1 \&$ isAllowed $=\mathrm{y}$

Qudhori, L. (2017). Pengidentikasian dan pengkreasian aposisi pada komentas haters di media sosial sebagai inovasi bahan ajar bahasa Indonesia di SMP kelas VII. Skripsi. Fakultas keguruan dan ilmu pendidikan Universitas Muhammadiyah Surakarta.

http://eprints.ums.ac.id/53312/1/01.N ASKAH\%20PUBLIKASI.pdf

Rinata, S, Hanifah, L, Rahayu, I, A. (2019). Bentuk sitilah-istilah upacara panggih pernikahan adat jawa: kajian etnolinguistik. Lite. 15(2). Retrieved from 
http://publikasi.dinus.ac.id/index.php /lite/article/view/2538/1705

Salfia, N. (2015). Nilai moral dalam novel $5 \mathrm{Cm}$ karya Donny Dhirgantoro. Jurnal humanika, 3(15), 1-18. Retrieved from http://ojs.uho.ac.id/index.php/HUMA NIKA/article/viewFile/595/pdf

Sari, N. (2017). Kekerasan perempuan dalam novel bak rambut dibelah tujuh karya Muhammad Makhdlori. Literasi. $1(2)$. 10.25157/literasi.v1i2.792. Retrieved from

https://jurnal.unigal.ac.id/index.ph p/literasi/article/viewFile/792/696

Sastromiharjo, A, Wimutikan, M, \& Mulyati, y. (2020). Analisis kontrastif fungsi kalimat tunggal bahasa Thai dan bahasa Indonesia sebagai bahan ajar BIPA Thailand. Seminar Internasional Riksa Bahasa. 19-28.

http://proceedings.upi.edu/index.php/ riksabahasa/article/download/1321/1 $\underline{200}$

Siregar, T. S. (2016). Menganalisis kalimat anak usia dini (2-3 tahun/siswa play group). Neliti. 80-93. Retrieved from https://media.neliti.com/media/public ations/76062-ID-menganalisiskalimat-pada-anak-usia-dini.pdf

Syarifah, I, L. (2017). Keterangan tempat pada kalimat dalam artikel bertema wisata di media cetak sebagai inovasi bahan ajar bahasa Indonesia SMP Kelas VII. Skripsi. Fakultas keguruan dan Ilmu pendidikan Universitas Mumahmmadiyah Surakarta. http://eprints.ums.ac.id/56505/1/01.\% 20NASKAH $\% 20$ PUBLIKASI.pdf

Tarmini, W. (2019). Sintaksis bahasa Indonesia. Jakarta. uhamka press.

Tasmin, A, C, Siska. (2020). Analisis frasa teks cerita pendek karya siswa kelas XI SMK Negeri 1 Padang Panjang. jurnal pendidikan bahasa dan Indonesia. 8 (3): 393-399. http://ejournal.unp.ac.id/index.php/pb s/article/download/108224/103257

Wahidah, B.Y.K. (2019). Komparasi berbagai definisi mengenai frasa dan kata majemuk dalam sosial google berdasarkan kajian sintaksis. Jurnal pendidikan, 4(5). Retrieved from http://ejournal.mandalanursa.org/inde x.php/JUPE/article/view/853/808

Wahyuni, R. T., Darmuki, A., \& Hasanudin, C. (2019). Analisis pola, fungsi, kategori, dan peran sintaksis pada kalimat tunggal dalam surat kabar Harian Kompas. Jurnal Bahtera-Jurnal Pendidikan Bahasa Sastra dan Budaya, 6(12). 659-670. Retrieved from http://ejournal.umpwr.ac.id/index.ph $\mathrm{p} / \mathrm{bahtera/article/view/6024.}$

Wardani, R. A. K. (2018). Kompeksitas kalimat dalam novel the secret of detya 2: Back to the secret karya kinta. Bapala, 5(1), 1-14. Retrieved from https://core.ac.uk/reader/230648470 
26 JURNAL PENDIDIKAN EDUTAMA, Vol.8, No.2 Juli 2021 